\title{
Coulisses
}

Revue de théâtre

19 | Hiver 1999

Varia

\section{Nostalgie d'un rêve généreux}

\section{Jacques Chevalier}

\section{OpenEdition}

Journals

Édition électronique

URL : https://journals.openedition.org/coulisses/5399

DOI : $10.4000 /$ coulisses.5399

ISSN : 2546-9460

\section{Éditeur}

Presses universitaires de Franche-Comté

\section{Édition imprimée}

Date de publication : 1 janvier 1999

Pagination : 16-17

ISBN : 2-913322-09-3

ISSN : $1150-594 \mathrm{X}$

\section{Référence électronique}

Jacques Chevalier, « Nostalgie d'un rêve généreux », Coulisses [En ligne], 19 | Hiver 1999, mis en ligne le 18 octobre 2019, consulté le 12 janvier 2022. URL : http://journals.openedition.org/coulisses/5399 ; DOI : https://doi.org/10.4000/coulisses.5399

Ce document a été généré automatiquement le 11 janvier 2022.

Coulisses 


\title{
Nostalgie d'un rêve généreux
}

\author{
Jacques Chevalier
}

1 Crainte et curiosité se partageaient mes pensées au moment d'assister à la représentation de la pièce Les Yeux rouges, sous-titrée Besançon Lip 1973-1998. Crainte de m'ennuyer à un spectacle qui, de toute évidence, n'allait ressembler en rien à une représentation théâtrale, laquelle, au sens traditionnel du terme, et selon la définition même du Larousse, est «l'art de représenter une action dramatique devant un public. » Les brochures de présentation nous annonçaient en effet un spectacle consistant en une série d'entretiens, au cours desquels quatre anciens de Lip devaient, chacun à leur tour, par la bouche d'un acteur, raconter leur expérience vécue au cours du conflit social qui avait fait résonner quelques temps, à travers la France, les noms de Lip et de Besançon. Curiosité, aussi, de découvrir de quelle manière le metteur en scène allait dépasser cette absence de spectacle qu'il avait délibérément voulue et parvenir à éveiller l'intérêt du spectateur.

2 Si l'action dramatique reste le ressort essentiel du théâtre et permet de soutenir l'intérêt d'un spectacle, elle peut n'être que prétexte à dessiner les contours des caractères des personnages et à illustrer passions et sentiments. C'est souvent le cas du théâtre classique qui, d'ailleurs, ne se prive pas d'utiliser le récit au lieu de le «mettre en scène ». L'évolution des formes théâtrales a même conduit certains auteurs, dans les années d'après-guerre, à réduire, voire à supprimer toute action dramatique. L'exemple le plus caractéristique en est donné par Beckett, pour qui l'absence d'action, dans Oh! les beaux jours, est un moyen d'exprimer ses conceptions métaphysiques.

D'autre part, des formes nouvelles de spectacle se sont développées par le truchement de l'audiovisuel. Films, pièces de théâtre peuvent être retransmis à la télévision, mais interviews, débats, tribunes, maintenant traditionnels, constituent, il me semble, des formes nouvelles de spectacle, puisant leur substance non plus dans la fiction mais dans la réalité. Le mot «spectacle» employé parfois à leur propos avec une connotation péjorative, ne change rien au fond. Par le truchement de la télévision, le monde est devenu un spectacle où, comme sur une scène, nous recherchons l'émotion théâtrale.

4 La notion de théâtre ayant - qui s'en plaindrait? - évolué au cours du temps, Les Yeux rouges, tels qu'ils nous sont présentés, c'est-à-dire sans « représentation d'une action 
dramatique ", trouvent naturellement leur place sur la scène du C.D.N. Il faut pourtant s'évader du seul débat technique et s'interroger sur le contenu des textes présentés au spectateur.

5 L'extrême simplicité du décor, la sobriété du jeu des acteurs, la plupart du temps assis, ainsi que l'attitude de l'interviewer, attentif et déférent, nous aident à concentrer notre attention sur les paroles prononcées par les «lips». Chacun d'entre eux exprime tout ce que lui a apporté le conflit : la découverte d'un monde peut-être jusque-là limité à la seule entreprise ou à la seule ville de Besançon; l'occasion d'une réflexion sur l'organisation de la société ; l'éventualité de vivre d'une manière différente les rapports du travail... Paulette, généreuse, Christiane, enthousiaste, Renée, rugueuse mais bonne, ont toutes trois pris la parole au moment des événements, elles ont exprimé leurs sentiments, participé pour certaines à la vente des montres, dénoncé les abus et le travail à la chaîne. Lip a traversé leur vie en y laissant son empreinte. Aujourd'hui retraitées, elles continuent à leur façon à militer et à aider leurs semblables : Paulette en participant à l'accueil des familles qui viennent visiter leurs parents prisonniers, Renée en réconfortant les déshérités qu'elle rencontre dans un foyer-restaurant.

6 La dernière interview, celle de Charles Piaget, dénonce l'affairisme, l'amour de l'argent, le copinage, et nous rappelle à l'application des règles de la démocratie qu'il avait mises en œuvre au sein de son syndicat.

7 Le CDN a eu raison de faire parler ces quatre « lips ». Ils ont ainsi exprimé la nostalgie d'un rêve qui n'a pu prendre corps mais qui les aide encore à vivre et se nourrissait sûrement de générosité.

\section{AUTEURS}

JACQUES CHEVALIER

Université Ouverte 